Journal of Social Sciences 7 (3): 358-363, 2011

ISSN 1549-3652

(C) 2011 Science Publications

\title{
Some Statistical Solutions and Methods in Evaluation of Efficiency in Sport and Effectiveness in the Phenomenon of Sportsmen' Training
}

\author{
${ }^{1}$ Gheorghe Săvoiu, ${ }^{2}$ Ion Iorga, ${ }^{3}$ Marian Crețu and ${ }^{4}$ Ion Mihăilă \\ ${ }^{1}$ Department of Accountancy and Management Information Systems, \\ Faculty of Economics, \\ ${ }^{2}$ Department of Evaluation and Academic Quality Assurance, Faculty of Sciences, \\ ${ }^{3}$ Department of Physical Education and Sports, \\ Faculty of Physical Education and Sports, \\ ${ }^{4}$ Department of Physical Education and Sports, \\ Faculty of Physical Education and Sports, University of Pitesti, Romania
}

\begin{abstract}
Problem statement: A general method for evaluation of efficiency in sport and effectiveness in the phenomenon of sportsmen's training was proposed. Approach: The method of four "E" was a frame method focused on communication and evaluation, where efficiency acquired an essential importance and its variation related to the initial programme, with its time or space details, respectively related to the effectiveness of coach Results: The practical results proved a high degree of coverage for proposed method in terms of efficiency and effectiveness in sports and training. Besides being successful in identifying regularities, generalizing the alternatives and emphasizing their fundamental contribution to majority of the results of sports organizations providing globally optimal results, due to high efficiency and lower computation time, the proposed approach could be considered an interesting candidate for easily characterization of the communication, evaluation and, finally, the decision-making processes, but especially of their aggregation in an ample process, the practical training for sportsmen phenomenon. Conclusion: Some conclusions of the proposed method were briefly presented for this new modern sports paradigm of modern coach and sportsmen, derived from economic thought. By comparing the alternatives of multidisciplinary analysis, considered as possible solutions of the method of four "E", regarded as a chain of logical approach of the type efficaciousness-degree of economy-efficiency-effectiveness, it was observed that statistical evaluation of indexes achieved better performances in terms of application, interpretation and the placement in hierarchical order and determination of the informational energy in terms of accuracy, using the probabilities of occurrence of effects, to the informational energy, completed and generalized the entirety.
\end{abstract}

Key words: Informational energy, team training, modern sport, efficaciousness-degree, degree of economy, sports efficiency, hierarchical order, general methodology, genetic algorithms, training programme

\section{INTRODUCTION}

The analysis of the efficiency is not a recent and exclusive concern of the economists, but even of the coaches in sports, of all managers, in general. The efficiency measurement emerges naturally from the distance between a real effect or observation and the empirical estimate of the theoretical effect. Between 1933 and 1951, economics and econometrics had revealed and quantified the economic concept of efficiency and F.H. Knight G. Debreu and T. C. Koopmans are the pioneers of scientific presentation of the results of their studies regarding the calculation of the efficiency. Kamatchi et al. (2009); Muralidhar et al. (2009); Ulrichs et al. (2009); Carifio and Perla (2010); Elforgani and Rahmat (2010); Eldos and
Almazyad (2010); Ismail et al. (2010); Cage and Kluck (2010); Iskandarani (2010) and Sarabian and Lee (2010) and others have brought important contributions through their recently published materials in the study of efficiency in sports and different domains, using both parametric and nonparametric methods. There have been made numerous applications of the stochastic frontier method, using diverse specifications of the production function, stochastic or determinist ones, parametric or nonparametric ones, based on cross-section or panel data. The authors of this study try to underline the applied efficiency in sport using new solutions and methods from statistics, mathematics, physics and genetic algorithms. 


\section{J. Social Sci., 7 (3): 358-363, 2011}

\section{MATERIALS AND METHODS}

There is neither communication between coach and sportsman without knowledge or sportive training and nor efficient results without communication and also there is no knowledge and no training without communication in sportive activity. The simplest model of representational communication is that of Karl Bühler synthesized by the first variant of the sendermessage-receiver type in the next Fig. 1.

In Roman Jakobson's intermediary variant there appear three other elements, code, channel and context (referent), offering the possibility of outlining, through pluralism, a potential model with six components: Sender-code-message-channel-context-receiver, as in the next Fig. 2.

In the cybernetic model of communication of Claude Shannon and Warren Weaver the contextual component is missing, the model avoids the semantic information, in favour of the selective one and it additionally contains three new components, the transmitter, the receiver and the noise and in order to constitute itself statistically and mathematically, that is to submit its object to measurement one resorts to a special characteristic of information, the fact that it benefits from an invariance all along a series of reversible operations and for this reason it quantizes in bits (which thus became units of measurement). Warren Weaver, through a relevant question, regarding the exactness with which the symbols of communication can be transmitted, generated the next Fig. 3 of the complex/classical system of communication.

The fundamental theorem of the statisticalmathematical theory of communication, considered valid for a channel without noise and for discreet signals, refers to the channel of communication having the capacity of $\mathrm{C}$ bits per second, receiving symbols from a source with the entropy of $\mathrm{H}$ bits per second (the information communicated) and it states that, thanks to the procedures of coding adequate to the sender it is possible to transmit symbols through the channel with an average debit considered close to the maximum value $\mathrm{C} / \mathrm{H}$. This fact, based on the background of the similarity with economy (production-exchangeconsumption) reduce sports communication to an exchange of messages, just as economy is an exchange of merchandise, which also allows to attach to the process of communication in sports activities one of the five methods of multidisciplinary analysis, considered as possible solutions of the method of the four "E", regarded as a chain of logical approach of the type efficaciousness-degree of economy-efficiencyeffectiveness:
- Efficaciousness in the model of communication message and noise

- Degree of economy in the model of communication: the $\mathrm{C} / \mathrm{H}$ relation or the limit of the resource of h type

- Efficiency in the model of communication maximization of the $\mathrm{C} / \mathrm{H}$ relation for a given level of $\mathrm{H}$

- Effectiveness in the model of communication monitoring/controlling the communication channel

- Statistical evaluation of indexes of procedural transformation through the law of equivalence and the dynamics of the factorial asymmetries (the index-numbers method)

- A delimitation of the informational transformation thresholds, of the maximum and minimum type, with the help of the law of the minimum and the law of the maximum (the method of the smallest squares through the use of the partial derivatives)

- A mathematical and physical interpretation of the economic relations centred upon the principle of losses, successive inequalities and of the inclinations of the slopes of effect and cause or of the angular coefficients of the $\mathrm{m}=\left(\mathrm{Y}_{1}-\mathrm{Y}_{2}\right) /\left(\mathrm{X}_{1}\right.$ $\mathrm{X}_{2}$ ) type

- A determination of the informational energy ( $\mathrm{S}=$ $\Sigma \mathrm{p}_{\mathrm{i}}^{2}$ )

- A modern sports efficiency vision with the help the general methodology support from genetic algorithms

This study underlines the primacy of efficiency and efficaciousness for sports activities and the tradition of statistics in identifying new applied solutions and methods. Practically any coach will have a training programme, which efficaciousness will transcribe into a matrix of the designed effects. The announced matrix model is achieved starting from the hypothesis that the management of the sportive organization will identify, name and draw up the main effects that give content to its training policy in hierarchical order as compared to the estimated probability of their occurrence (Table 1, the sum of the probabilities being equal to 1).

The training programme as a matrix of the designed effects and placed in hierarchical order according to their occurrence probability

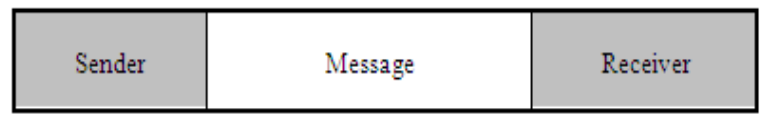

Fig. 1: Karl Bühler's communication model, sendermessage-receiver 


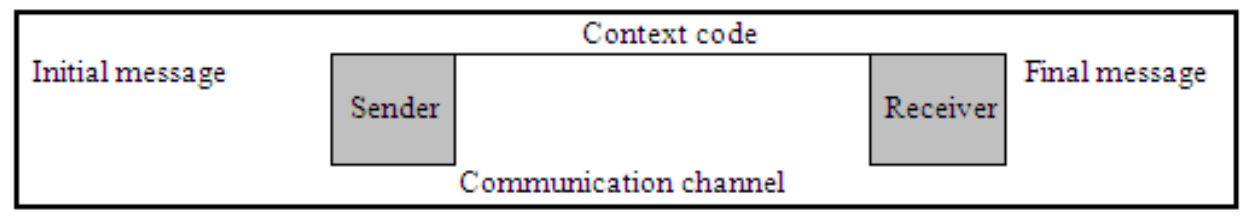

Fig. 2: Reunited model of communication (Karl Bühler - Roman Jakobson)

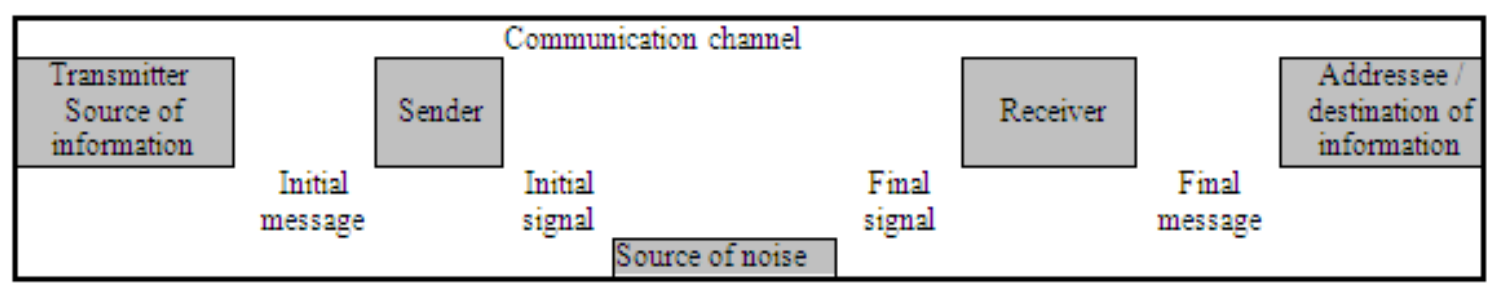

Fig. 3: The systemic model of communication (Claude Shannon-Warren Weaver)

Table 1: The training programme as a matrix of the designed effects and placed in hierarchical order according to their occurrence probability The designed effect and placed in hierarchical order according to the occurrence probability

\begin{tabular}{|c|c|c|c|}
\hline & & & \\
\hline $\begin{array}{l}-A- \\
E_{1}\end{array}$ & $\begin{array}{l}\text { - B - } \\
\mathrm{Km} .\end{array}$ & $-1-$ & $\begin{array}{l}-\mathrm{p}_{\mathrm{a}}- \\
0,20\end{array}$ \\
\hline $\mathrm{E}_{2}$ & $\%$ & & 0,12 \\
\hline $\mathrm{E}_{3}$ & $\mathrm{Kg}$. & & 0,10 \\
\hline$\ldots$ & $\ldots$ & & $\ldots$ \\
\hline $\begin{array}{l}\mathrm{E}_{\mathrm{n}} \\
\text { Total }\end{array}$ & $\begin{array}{l}\text { hours } \\
n_{n}-1\end{array}$ & & 0,01 \\
\hline
\end{tabular}

Table 2: The matrix of the prognosticated and re-placed in hierarchical order effects according to the final importance The effect designed and re-placed in hierarchical order according to the final importance

final importance $\quad$ U.M

\begin{tabular}{|c|c|c|c|}
\hline $\begin{array}{l}\text { The designed level } \\
\text { occurrence probability } \\
\text { of the effect }\end{array}$ & $\begin{array}{l}\text { The estimated } \\
\text { strategic impact }\end{array}$ & The estimated & Final importance (OEp) \\
\hline \multirow[t]{6}{*}{$-1-$} & $-\mathrm{p}_{\mathrm{a}}-$ & $-p_{j}-$ & $\begin{array}{l}\left(\mathrm{p}_{\mathrm{a}} \times \mathrm{p}_{\mathrm{j}}\right) \\
00200\end{array}$ \\
\hline & 0,10 & 0,15 & 0,0150 \\
\hline & 0,12 & 0,08 & 0,0960 \\
\hline & $\ldots$ & $\ldots$ & $\ldots$ \\
\hline & 0,01 & 0,01 & 0,0001 \\
\hline & $\Sigma p_{a}=1,00$ & $\Sigma \mathrm{p}_{\mathrm{j}}=1,00$ & - \\
\hline
\end{tabular}

Table 3: The evaluation of the average coefficients given by the members of the coaches for the selection of the optimum variant of team training Number of coaches

\begin{tabular}{|c|c|c|c|c|}
\hline $\mathrm{E}_{1}$ & $\mathrm{E}_{2}$ & $E_{j} \ldots$ & $\mathrm{E}_{\mathrm{n}}$ & \\
\hline Variant $\mathrm{I}=\mathrm{k}_{1}$ & $\mathrm{E}_{11}$ & $\mathrm{E}_{21}$ & $\mathrm{Ej}_{1}$ & $\mathrm{E}_{\mathrm{n} 1}$ \\
\hline Variant II $=\mathrm{k}_{2}$ & $\mathrm{E}_{12}$ & $\mathrm{E}_{22}$ & $\mathrm{E}_{\mathrm{j} 2}$ & $\mathrm{E}_{\mathrm{n} 2}$ \\
\hline Variant $" i "=k_{i}$ & $\mathrm{E}_{1 \mathrm{i}}$ & $\ddot{E_{2 i}}$ & $\dddot{E_{j i}}$ & $\dddot{E_{n i}}$ \\
\hline $\begin{array}{l}\text { Variant " } n "=k_{n} \\
\text { Average coefficient }\end{array}$ & $\mathrm{E}_{1 \mathrm{n}}$ & $\mathrm{E}_{2 \mathrm{n}}$ & $\dddot{E_{j n}}$ & $\mathrm{E}_{\mathrm{nn}}$ \\
\hline $\mathrm{Em}_{\mathrm{ji}}=\left(\Sigma \mathrm{E}_{\mathrm{ji}} \mathrm{k}_{\mathrm{i}}\right) /\left(\Sigma \mathrm{k}_{\mathrm{i}}\right)$ & $\mathrm{Em}_{1}=\left(\Sigma \mathrm{E}_{1 \mathrm{i}} \mathrm{k}_{\mathrm{i}}\right) /\left(\Sigma \mathrm{k}_{\mathrm{i}}\right)$ & $\mathrm{Em}_{2}=\left(\Sigma \mathrm{E}_{2 \mathrm{i}} \mathrm{k}_{\mathrm{i}}\right) /\left(\Sigma \mathrm{k}_{\mathrm{i}}\right)$ & $E m_{\mathrm{j}}=\left(\Sigma \mathrm{E}_{\mathrm{ji}} \mathrm{k}_{\mathrm{i}}\right) /\left(\Sigma \mathrm{k}_{\mathrm{i}}\right)$ & $\mathrm{Em}_{\mathrm{n}}=\left(\Sigma \mathrm{E}_{\mathrm{ni}} \mathrm{k}_{\mathrm{i}}\right) /\left(\Sigma \mathrm{k}_{\mathrm{i}}\right)$ \\
\hline Hierarchy of effects & \multicolumn{4}{|c|}{ It is established according to the final relationship ">" or" $<$ " type among all Emj $\mathrm{j}_{\mathrm{i}}$} \\
\hline
\end{tabular}




\section{J. Social Sci., 7 (3): 358-363, 2011}

Table 4: The matrix of the efforts (consumptions) necessary according to the risk of non-degree of economy (competitiveness) of the effort

\begin{tabular}{|c|c|c|c|c|c|c|}
\hline $\begin{array}{l}\text { The designed effect } \\
\text { and re-placed in } \\
\text { hierarchical order }\end{array}$ & U.M. & The designed level & $\begin{array}{l}\text { The necessary } \\
\text { effort (consumption) }\end{array}$ & U.M. & $\begin{array}{l}\text { The necessary } \\
\text { level of effort }\end{array}$ & $\begin{array}{l}\text { The risk of non-degree } \\
\text { of economy of the effort }\end{array}$ \\
\hline$-\mathrm{A}-$ & $-\mathrm{B}-$ & $-1-$ & - Cnj- & $-\mathrm{D}-$ & $-2-$ & - pCnj - \\
\hline \multirow[t]{4}{*}{$\mathrm{E}_{1}$} & $\mathrm{Km}$. & & $\mathrm{C}_{11}$ & $\mathrm{Km}$. & & 0,08 \\
\hline & & & $\mathrm{C}_{12}$ & $\mathrm{Km}$. & & 0,06 \\
\hline & & & $\mathrm{C}_{13}$ & $\mathrm{Km}$. & & 0,04 \\
\hline & & & $\mathrm{C}_{14}$ & $\mathrm{Km}$. & & 0,02 \\
\hline $\mathrm{E}_{2}$ & $\%$ & & $\mathrm{C}_{21}$ & $\%$ & & 0,10 \\
\hline$\ldots$ & $\begin{array}{l}\ldots \\
\text { hours }\end{array}$ & & 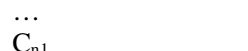 & $\begin{array}{l}\ldots . . \\
\text { hours }\end{array}$ & & $\ldots$ \\
\hline & & Total & & nours & & $\sum \mathrm{pC}_{\mathrm{nj}}=1,00$ \\
\hline
\end{tabular}

Table 5: The matrix of the prognosticated effects and of the necessary efforts (consumptions of resources) re-placed in hierarchical order according to the final importance

\begin{tabular}{|c|c|c|c|c|c|c|c|c|}
\hline $\begin{array}{l}\text { The designed } \\
\text { effect replaced } \\
\text { in hierarchical } \\
\text { order }\end{array}$ & U.M. & $\begin{array}{l}\text { The designed } \\
\text { level }\end{array}$ & $\begin{array}{l}\text { The necessary } \\
\text { effort (consumption } \\
\text { of resources) }\end{array}$ & U.M & $\begin{array}{l}\text { The necessary } \\
\text { level of effort }\end{array}$ & $\begin{array}{l}\text { The risk of } \\
\text { non- degree } \\
\text { of economy } \\
\text { of the effort }\end{array}$ & $\begin{array}{l}\text { The estimated } \\
\text { strategic impact }\end{array}$ & $\begin{array}{l}\text { The final } \\
\text { importance } \\
\text { (OCp) }\end{array}$ \\
\hline \multirow{5}{*}{$\begin{array}{l}-\mathrm{A}- \\
\mathrm{E}_{1}\end{array}$} & - B - & $-1-$ & $-\mathrm{C}-$ & - D - & $-2-$ & $-\mathrm{pC}_{\mathrm{nj}}-$ & $-\mathrm{pj}-$ & $-\mathrm{pC}_{\mathrm{nj}} \times \mathrm{p}_{\mathrm{j}}$ \\
\hline & $\mathrm{Kg}$. & & $\mathrm{C}_{11}$ & $\mathrm{Kg}$. & & 0,08 & 0,04 & 0,0032 \\
\hline & & & $\mathrm{C}_{12}$ & $\mathrm{Kg}$. & & 0,06 & 0,03 & 0,0018 \\
\hline & & & $\mathrm{C}_{13}$ & $\mathrm{Kg}$. & & 0,04 & 0,02 & 0,0008 \\
\hline & & & $\mathrm{C}_{14}$ & $\mathrm{Kg}$. & & 0,02 & 0,01 & 0,0002 \\
\hline $\mathrm{E}_{2}$ & $\%$ & & $\mathrm{C}_{21}$ & $\%$ & & 0,10 & 0,15 & 0,0150 \\
\hline \multirow{3}{*}{$\ldots$} & $\ldots$ & & $\ldots$ & $\ldots$ & & $\ldots$ & .. & \\
\hline & hours & & $\mathrm{C}_{\mathrm{n} 1}$ & Hours & & 0,01 & 0,01 & 0,0001 \\
\hline & & Total & & & & $\Sigma \mathrm{pC}_{\mathrm{nj}}=1,00$ & $\Sigma \mathrm{p}_{\mathrm{j}}=1,00$ & - \\
\hline
\end{tabular}

The specificity and originality of the training strategy finds its expression in a second matrix or Table 2, which multiplies the estimated occurrence probability of the effect with its impact as such and generates a new hierarchy of the effects according to the explanatory factors. The solution for measuring the degree of economy (competitiveness) resumes the procedure already mentioned and presented, including here a larger spectrum of analysis of the efficaciousness and the degree of economy or competitiveness (than the usual one in the classic training, where the efficiency and effectiveness of the training its management are reference points of the whole in the efficaciousness of sportive organization, Table 3 and 4), inventorying the efforts, in direct dependence on the effects already designed with specific units of measurement, but also potentially detailed or multiplied as compared to the effects placed in hierarchical order as estimated occurrence probability, according to the following matrix.

The matrix instrument identifies in an associated way the main efforts (consumptions of resources, Table 5 ) in parallel with the effects re-placed in hierarchical order. The value of the aggregate of the risks of all effort (consumption of resouces) components, reunited on the level of distinct category of designed effort, coincides with the estimated occurrence probability of the category of effort:

$$
\mathrm{pC}_{11}+\mathrm{pC}_{12}+\mathrm{pC}_{13}+\mathrm{pC}_{14}=\mathrm{p}_{\mathrm{a}} \text { for } \mathrm{E}_{1} \text { and } \mathrm{pC}_{11}
$$

$+\mathrm{pC}_{12}+\mathrm{pC}_{13}+\ldots+\mathrm{pC}_{\mathrm{nj}}=\Sigma \mathrm{p}_{\mathrm{a}}=1,000$

The managerial strategy in the field of efforts (consumptions of resources) is to be found still in a matrix capitalizing the multiplication of the risk of nondegree of economy with its impact and without generating a new hierarchy of the effects, but only a replacing in hierarchical order of efforts within the classes of effort afferent to a distinct category of effect, as in the next table 6 and 7 .

The presented risks and probabilities can be determined analogously, starting either from the same subjective or objective criteria, recorded in the case of efficaciousness or from a generalized FishbeinRosenberg scale of report.

\section{RESULTS}

The two results of the products between the occurrence probability of the effects and their impact and between the risk of non-degree of economy of the efforts and their impact defined as informational energy of the designed effect (OEp) and informational energy of the designed effort (OCp), through analogy with the Onicescu informational energy defined as product of probabilities can be considered as essential indicators in the analysis of efficiency and effectiveness in the general plan of the organization 
J. Social Sci., 7 (3): 358-363, 2011

Table 6: The determination of the efficiency of activity in economy

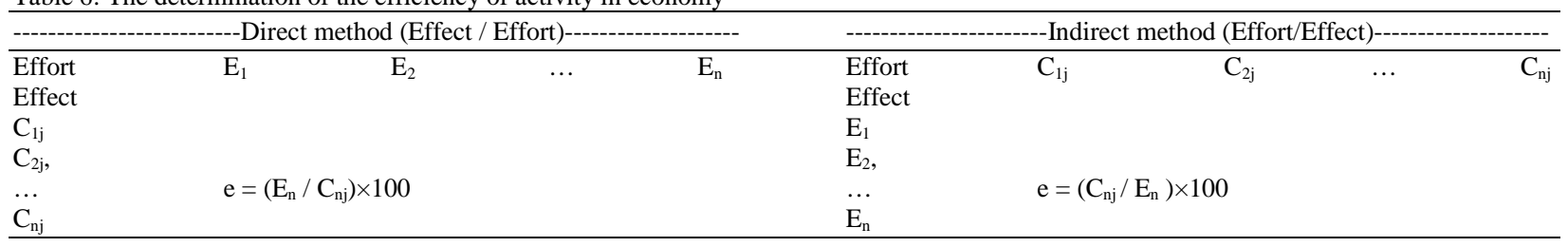

The conclusion of the degree of economy (competitiveness) brings along a rendering relative of the importance of the effect and an emphasis of the significance of the balance between results and resources or between effects and consumptions $(E>C)$, as well as of the absolute change $(\Delta=\mathrm{E}-\mathrm{C}$ or $\Delta=\Sigma \mathrm{E}-$ $\Sigma C)$. One can thus appreciate that the degree of economy of an activity, exclusively in the situation in which there appear economies determined as positive difference between effects and efforts $(\mathrm{E}-\mathrm{C}>0)$. The analysis of the relationship effect-effort or consumptionresult practically defines the essence of the coach of the team in the sportive organization. The coach is bound to analyze which is the minimum combination of efforts (inputs), for a designed level of the effect (the output), or, disposing of some limited efforts or fixed inputs, which is the maximum output, the one that can be obtained through their use:

The training programs that apply this analysis permanently are obviously called expressions of the efficient thinking of a modern coach. A more profound level of thinking thus starts from efficaciousness and degree of economy (competitiveness) and evolves towards a paradigm based on the principles that correctly delimitate their existential environment and the real relational one of the effect-effort or consumption-result effect. This approach based on principles is founded on the new thinking of the sportive organization's efficiency and its management. The efficiency expresses the relationship between efforts and effects, through specific indicators resulted from abstracted and evaluated associations, such as the association of the efforts (consumptions) of the resources as designed and accomplished level, in parallel with the association between the level of the designed and accomplished effects, the temporal (chronological) association or the spatial one of the effort/effect or effect/effort type. In practice two criteria of efficiency are attached: the criterion of saving through the relation to effort and the criterion of intensification, through correlation with the effect.
Approached from an applicable point of view, efficiency is defined through two methods, respectively through the direct one as relationship between any of the values of the effects or of the results $\left(E_{1}, E_{2}, \ldots, E n\right)$ and any of the values of the efforts or consumptions $\left(\mathrm{Cn}_{1}, \mathrm{Cn}_{2}, \ldots, \mathrm{Cnj}\right)$, or through the indirect method, respectively described as relationship between efforts or consumptions $\left(\mathrm{Cn}_{1}, \mathrm{Cn}_{2}, \ldots\right.$, $\mathrm{Cnj})$ and effects or results $\left(\mathrm{E}_{1}, \mathrm{E}_{2}, \ldots, \mathrm{En}\right)$.

The determination of the efficiency of activity in economy: No matter how modelling and methodical, the thinking of efficiency still remains a static and purely observing one. At this stage one can appreciate that the whole defines a new method, simply called the method of the four " $E$ " that will impose the final appreciation of the training for the sportive organization.

By comparing the alternatives of multidisciplinary analysis, considered as possible solutions of the method of the four "E", regarded as a chain of logical approach of the type efficaciousness-degree of economyefficiency-effectiveness, it is observed that statistical evaluation of indexes achieved better performances in terms of application, interpretation and the placement in hierarchical order and the determination of the informational energy in terms of accuracy, using the probabilities of occurrence of the effects, to the informational energy, complete and generalize the entirety. Some practical results of the method, from the training of the team in the sportive organization of the Faculty of Physical Education and Sports, underline the importance and allow the selection of the modern coach and sportsmen, derived from economic thought and based on the effects achieved or better performances in terms of the estimated occurrence probability of the effect and of the risk of non-degree of economy of the effort. From the five teams involved in the evaluation of efficiency in sport and effectiveness in the phenomenon of sportsmen' training using the method of four "E" one needs a better communication between coach and sportsmen, especially of the designed level of training estimated occurrence correlated with probability of the effect and two need a better estimation of the strategic impact and of the risk of non-degree of economy of the effort. 
Table 7: Walsh indices used for effects or efforts on the impact, on the occurrence probability or on the risk of economy's non-degree

\begin{tabular}{|c|c|c|c|}
\hline Walsh index used for effect & emphasis on the & Walsh index used for efforts with emp & on the \\
\hline$\sum_{\mathrm{i}=1}^{\mathrm{n}} \mathrm{p}_{\mathrm{j} 1} \sqrt{\mathrm{p}_{\mathrm{a} 1} \times \mathrm{p}_{\mathrm{a} 0}}$ & $\sum_{\mathrm{i}=1}^{\mathrm{n}} \mathrm{p}_{\mathrm{a} 1} \sqrt{\mathrm{p}_{\mathrm{j} 1} \times \mathrm{p}_{\mathrm{j} 0}}$ & $\sum_{\mathrm{i}=1}^{\mathrm{n}} \mathrm{p}_{\mathrm{j} 1} \sqrt{\left(\mathrm{p}_{\mathrm{Cn}}\right)_{\mathrm{j} 1} \times\left(\mathrm{p}_{\mathrm{Cn}}\right)_{\mathrm{j} 0}}$ & $\sum_{i=1}\left(p_{C n}\right)_{j 1} \sqrt{p_{j 1}} \times p_{j 0}$ \\
\hline$\sum_{\mathrm{i}=1} \mathrm{p}_{\mathrm{j} 0} \sqrt{\mathrm{p}_{\mathrm{a} 1} \times \mathrm{p}_{\mathrm{a} 0}}$ & $\sum_{\mathrm{i}=1} \mathrm{p}_{\mathrm{a} 0} \sqrt{\mathrm{p}_{\mathrm{j} 1} \times \mathrm{p}_{\mathrm{j} 0}}$ & $\sum_{i=1} p_{j 0} \sqrt{\left(p_{C n}\right)_{j 1} \times\left(p_{C n}\right)_{j 0}}$ & 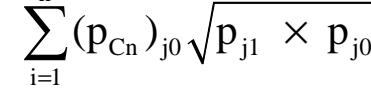 \\
\hline Impact & occurrence probability & impact & risk of economy's non-degree \\
\hline
\end{tabular}

\section{DISCUSSION}

The thinking of effectiveness detaches from the thinking of efficiency, re-interpreting it in time, in relation to the level of the effect and of the effort, both designed and effective. The effectiveness of communication and of negotiation as bilateral or multilateral type of communication successful and accomplished through common agreement becomes instrument of appreciation of the whole sportive preparation and training of the team in the sportive organization. The statement according to which the decision of a team of coaches is much more effective has more chances of being correct in relation to the idea that the individual coach's decision is the expression of the maximization of the same effectiveness. Communication at the level of the team of coaches does not generate totally new information, although it could be possible to identify in the communicated message a series of knowledge that initially has not been taken into consideration. In the team of coaches through double communication, specific to the negotiation within the variants of design of the effects and efforts, a better selection can be made between the examined alternative projections, but it is also possible to have a loss of information and precision as well (it is true, not as high as the loss in case of a unique point of decision presented and accepted). But according to the observations from the statistics of the teams of coaches there are quite enough cases (approximately a third), in which the team's final decision is weaker than the best variant of the top coach's unique initial decision (thus individual). This takes place only in the hypothesis in which the knowledge is fragile and there are many pieces of erroneous information (the difference between the designed and the effective informational energies being much above the 5\%, limit frequently accepted in the economic decision), the decisional communication of the team of coaches having high chances to lead to cognitive performances inferior to the individual ones.

\section{CONCLUSION}

Among the five methods of analysis, considered as possible solutions of the method of the four "E," only four are the result of the direct contribution of statistics:

- The statistical evaluation of the procedural transformation indexes through the law of equivalence and the dynamics of the factorial asymmetries, respectively through the method of indexes which has the Walsh index as adequate solution, applied to effects and to efforts both in their temporal evolution and in relation to the initial managerial plan

- The delimitation of the informational transformation thresholds, of maximum and minimum type, with the contribution of the law of the minimum and of the law of the maximum (the method of the smallest squares by using the partial differentials)

- The statistical interpretation of the differences of slope of the effect and effort ramps or of the different angular coefficients of $\mathrm{m}=\left(\mathrm{Y}_{1^{-}} \mathrm{Y}_{2}\right) /\left(\mathrm{X}_{1^{-}}\right.$ $\mathrm{X}_{2}$ ) type

- The determination of the informational energy, but not in the classical formula $\left(\mathrm{S}=\Sigma \mathrm{p}_{\mathrm{i}}^{2}\right)$, but either as informational energy of the designed effect $\left(\mathrm{OEp}_{0}\right.$ $\left.=\Sigma p_{a 0} \times p_{j 0}\right)$, compared to the informational energy of the achieved effect $\left(\mathrm{OEp}_{1}=\Sigma \mathrm{p}_{\mathrm{a} 1} \times \mathrm{p}_{\mathrm{j} 1}\right)$ or as informational energy of the designed effort $\left(\mathrm{OCp}_{0}\right.$ $=\Sigma \mathrm{pC}_{\mathrm{nj} 0} \times \mathrm{p}_{\mathrm{j} 0}$ ) compared to the informational energy of the achieved effort $\left(\mathrm{OCp}_{1}=\Sigma \mathrm{pC}_{\mathrm{nj} 1} \times \mathrm{p}_{\mathrm{j} 1}\right)$. The differences higher than $5 \%$ become relevant to the analysis of the effectiveness (effective value being below $95 \%$ of the projected one)

- The determination of a modern sports efficiency vision with the help the general methodology support from genetic algorithms

In essence an effectiveness measured this way can be detailed on three degrees of importance: $1^{\text {st }}$ degree 
effectiveness, which will compare the efficaciousness (the effects), 2nd degree effectiveness, which will compare the degree of economy (effects and efforts, but also the difference between them) and 3rd degree effectiveness which will compare the efficiency.

\section{REFERENCES}

Cage, E.A. and A.S. Kluck, 2010. The path to treatment: Does It matter? Relapse and the reason for seeking Treatment. Curr. Res. Psychol., 1: 2934. DOI: $10.3844 /$ crpsp.2010.29.34

Carifio, J. and R.J. Perla, 2010. Towards the decline and fall of radical and educational constructivism (Mark I). Curr. Res. Psychol., 1: 1-15. DOI: 10.3844/crpsp.2010.1.15

Eldos, T.M. and A.S. Almazyad, 2010. Adaptive resonance theory training parameters: pretty good sets. J. Comput. Sci., 6: 1443-1449. DOI: 10.3844 jcssp. 2010.1438 .1444

Elforgani, M.S. and Rahmat, I.2010. An Investigation of Factors Influencing Design Team Attributes in Green Buildings. Am. J. Applied Sci., 7: 976-986. DOI:

10.3844/ajassp.2010.976.986http://docsdrive.com/p dfs/ansinet/pjn/2010/844-852.pdf

http://www.doaj.org/doaj?func=abstract\&id=626541 http://www.doaj.org/doaj?func=abstract\&id=694034

Iskandarani, M.Z., 2010. Head gesture analysis using matrix group displacement algorithm. J. Comput. Sci., 6 : 1362-1365. DOI: 10.3844/jcssp.2010.1362.1365

Ismail, A.R., M.R.A. Mansor, M.F.M. Ali, S. Jaafar and N.K. Makhtar, 2010. Biomechanical Analysis of Ankle Force: A Case Study for Instep Kicking. Am. J. Applied Sci., 7: 323-330. DOI: 10.3844/AJASSP.2010.323.330

Kamatchi, C., H. Magesh, U. Sekhar and R. Vaidyanathan, 2009. Identification of clonal clusters of klebsiella pneumoniae isolates from chennai by extended spectrum beta lactamase genotyping and antibiotic resistance phenotyping analysis. Am. J. Infect. Dis., 5: 74-82. DOI: 10.3844/AJIDSP.2009.74.82

Muralidhar, T.S., A. Balaji, C. Bandopadhyay and S.L. Shantha, 2009. Cytoprotective effect of ulgen, a polyherbal formulation against physical and chemical factor induced gastric ulcers in wister albino rats. Am. J. Pharmacol. Toxicol., 4: 80-84. DOI: 10.3844/ajptsp.2009.80.84 http://www.cabdirect.org/abstracts/20093331524. html;jsessionid=F331FF3E7FA36820373FEB199 3D4475E
Nazif, H. and L.S. Lee, 2010. Optimized Crossover Genetic Algorithm for Vehicle Routing Problem with Time Windows. Am. J. Applied Sci., 7: 95101. DOI: 10.3844/ajassp.2010.95.101

Omar, M., S.L. Syed-Abdullah and A. Yasin, 2011. The impact of agile approach on software engineering teams. Am. J. Econ. Bus. Admin., 3: 12-17. DOI: 10.3844/ajebasp.2011.12.17

Sadik, A., 2010. Orphanage children in Ghana: Are their dietary needs met. Pak. J. Nutr., 9: 844-852. DOI: $10.3923 /$ PJN.2010.844.852

Sarabian, M. and L.V. Lee, 2010. A Modified Partially Mapped MultiCrossover Genetic Algorithm for Two-Dimensional Bin Packing Problem. J. Math. Stat., 6: 157-162. DOI:10.3844/JMSSP.2010.157.162

Săvoiu, G., I. Iorga-Simăn, C. Manea and I. Ştefănescu, 2010. Econometrics models versus physics models and their final connections with social economic reality, the educational system and scientific research. economy. transdisciplinarity. Cognition, 13: 32-44. http://www.ugb.ro/etc/etc2010no2/s0103\%20\%281 $\% 29 . p d f$

Soma Basu and S. K. Datta, 2010. The Success Story of Voluntary Retirement Scheme in National Carbon Company: A Unit of Eveready Industries India Ltd. American Journal of Economics and Business Administration, 2 : 157-159. DOI: 10.3844/AJEBASP.2010.157.159

Ulrichs, C., U. Schmidt, T. Mucha-Pelzer, A. Goswami and I. Mewis, 2009. Hard coal fly ash and silicaeffect of fine particulate matter deposits on brassica chinensis. Am. J. Agric. Biol. Sci., 4: 24-31. DOI: 10.3844/AJABSSP.2009.24.31

Yongzhi Gao, Weijun Gao, Ji Xuan and Yutaka Tonooka, 2010. Estimation of NonResidential Building Energy Consumption. American Journal of Engineering and Applied Sciences, 3: 529-533. DOI: 10.3844/ajeassp. 2010.529.533

Zhu, Z., D.X. Li and M. Zhang, 2010. Performance modeling and optimization of hierarchical B pictures based on directed tree. Inform. Technol. J., 9: 643-65. DOI: 10.3923/ITJ.2010.643.651 